\title{
IncobotulinumtoxinA in aesthetics: Russian multidisciplinary expert consensus recommendations
}

This article was published in the following Dove Press journal:

Clinical, Cosmetic and Investigational Dermatology

5 June 2015

Number of times this article has been viewed

\section{Yana Yutskovskaya' \\ Elena Gubanova ${ }^{2}$ \\ Irina Khrustaleva ${ }^{3}$ \\ Vasiliy Atamanov ${ }^{4}$ \\ Anastasiya Saybel ${ }^{5}$ \\ Elena Parsagashvili ${ }^{6}$ \\ Irina Dmitrieva ${ }^{7}$ \\ Elena Sanchez ${ }^{8}$ \\ Natalia Lapatina ${ }^{9}$ \\ Tatiana Korolkova ${ }^{10}$ \\ Alena Saromytskaya"I \\ Elena Goltsova ${ }^{12}$ \\ Elmira Satardinova ${ }^{13}$}

'Department of Dermatovenereology and Cosmetology, Pacific State Medical

University, Vladivostock, ' $D$ Department of

Skin and Venereal Diseases, Postgraduate

Medical Institute, Moscow National

University of Food Production, Moscow,

${ }^{3}$ Department of Plastic Surgery, IP Pavlov

Medical State University, St Petersburg,

${ }^{4}$ Department of Reconstructive and

Plastic Surgery, SN Fedorova, Federal

State Institution, Novosibirsk, ${ }^{5} \mathrm{Clinic}$

Ideal, Laser Technologies Center,

Moscow, ${ }^{6}$ Aestima-clinic, ${ }^{7}$ Clinic

"Academy", St Petersburg, ${ }^{8}$ Eklan Medical

Center of Cosmetological Correction,

${ }^{9} \mathrm{Clinic}$ of Aesthetic Medicine and

Plastic Surgery, Moscow, ${ }^{10}$ Department

of Cosmetology, II Mechnikov North-

Western State Medical University,

St Petersburg, "Plastic Surgery Clinic,

Center of Aesthetic Medicine and

Beauty Cosmetology, 12 “'Neo-Clinic,"

Tyumen, ${ }^{13}$ Botulinum Toxin Therapy

Department, Diagnostic Center of

the Irkutsk State Medical Academy of

Postgraduate Education, Irkutsk, Russia

Correspondence: Yana Yutskovskaya Budennogo Avenue 26, Building I,

Moscow, I05II8, Russia

Tel +79853880077

Email yutsk@mail.ru
Background: Although there are various international consensus recommendations on the use of botulinum neurotoxin type A (BoNT/A) in facial aesthetics, there are no global or Russian guidelines on the optimal dose of incobotulinumtoxinA, free from complexing proteins, within specific aesthetic indications. This article reports the outcomes of two expert consensus meetings, conducted to review and analyze efficacy and tolerability data for incobotulinumtoxinA in various facial aesthetic indications and to give expert consensus recommendations to ensure best clinical practice among Russian clinicians.

Methods: Thirteen dermatology and/or plastic surgery experts attended meetings held in Paris, France (November 2013), and Moscow, Russia (March 2014). The expert group reviewed and analyzed the existing evidence, consensus recommendations, and Russian experts' extensive practical experience of incobotulinumtoxinA in aesthetics to reach consensus on optimal doses, potential dose adjustments, and injection sites of incobotulinumtoxinA for facial aesthetics.

Results: All experts developed guidance on the optimal doses for incobotulinumtoxinA treatment of different regions of the upper and lower face. The expert panel agreed that there are no differences in the efficacy and duration of the effect between the four BoNT/As that are commercially available for facial aesthetic indications in Russia and that, when administered correctly, all BoNT/As can achieve optimal results. Experts also agreed that nonresponse to BoNT/A can be caused by neutralizing antibodies.

Conclusion: On the basis of the scientific and clinical evidence available for incobotulinumtoxinA, coupled with the extensive clinical experience of the consensus group, experts recommended the optimal doses of incobotulinumtoxinA effective for treatment of wrinkles of the upper and lower face to achieve the expected aesthetic outcome. These first Russian guidelines on the optimal use of incobotulinumtoxinA for augmentation of glabellar lines, periorbital wrinkles, forehead lines, bunny lines, perioral wrinkles, depressor anguli oris, mentalis, masseters and platysmal bands, and performing the Nefertiti lift, are presented here.

Keywords: incobotulinumtoxinA, free from complexing proteins, consensus guidelines, facial lines, dosage, aesthetics, Russia

\section{Introduction}

Botulinum neurotoxin type A (BoNT/A) effectively diminishes rhytides of the upper and lower face by inhibiting hyperdynamic musculature that can lead to wrinkle and line formation. ${ }^{1-12}$ At this time, there are a number of BoNT/A preparations available for aesthetic use on the international market, all of which differ in terms of their method of manufacture, composition, potency, and approved indications. ${ }^{13-16}$ In Russia, four preparations of BoNT/A are currently approved for aesthetic use: onabotulinumtoxinA (Vistabel ${ }^{\circledR}$; Allergan Inc., Irvine, CA, USA), abobotulinumtoxinA (Azzalure ${ }^{\circledR}$; 
Ipsen Ltd, Slough, UK, distributed by Galderma in Russia), Lantox $^{\circledR}$ (Lanzhou Institute of Biological Products, Lanzhou, People's Republic of China), and incobotulinumtoxinA, free from complexing proteins (XEOMIN Cosmetic ${ }^{\mathrm{TM}} / \mathrm{Xeomin}^{\circledR} /$ Xeomeen ${ }^{\circledR} /$ Bocouture $^{\circledR}$; Merz Pharmaceuticals GmbH, Frankfurt, Germany). ${ }^{17}$

Since 2003, onabotulinumtoxinA has been approved for the treatment of a number of aesthetic indications in Russia, including facial wrinkles and facial asymmetry. ${ }^{17}$ AbobotulinumtoxinA is indicated for the treatment of mimic wrinkles and hyperhidrosis. Lanzhou's BoNT/A came to the Russian market in 2008 and is indicated for the correction of age-related changes. ${ }^{17}$ IncobotulinumtoxinA has been available in Russia since 2008 and is also indicated for the correction of hyperkinetic mimic wrinkles. ${ }^{17}$ However, unlike any of the conventional botulinum neurotoxin preparations, incobotulinumtoxinA is free from complexing proteins, which may confer clinical benefits in terms of reduced potential for immunostimulating activity. ${ }^{18,19}$

Given these differences in BoNT/A preparations, a need exists for well-defined guidance on the optimal treatment doses for specific BoNT/A preparations, such as incobotulinumtoxinA for facial aesthetic procedures in Russia, where such procedures are particularly popular, especially among women who are 35-50 years of age.

\section{Statement of need}

There are currently no Russian guidelines on the optimal dose of incobotulinumtoxinA for specific aesthetic indications, although scales for the assessment of Russian facial aesthetics have been published in the past. ${ }^{20}$ Consensus recommendations for the assessment of facial aesthetics do exist for other countries; ${ }^{16,21-25}$ however, these may not be suitable for Russian clinicians if differences in aesthetic ideals exist.

As in the rest of the world, the concept of "ideal beauty" in Russia is based on the ancient model of proportional beauty. ${ }^{26}$ However, as there are more than 170 ethnic groups in Russia, ${ }^{27}$ gaining consensus on a Russian beauty ideal may be difficult.

Russians place great importance on maintaining a youthful appearance. This is particularly true of Russian women, who are highly motivated to look younger for longer, thus making them open to treatment with injectables. Despite this, within Russia, a barrier still remains with regard to the social acceptability of such treatment.

By far the most common age group presenting for aesthetic treatment in Russia is 35- to 50-year-old women, ${ }^{28}$ which is in agreement with the most recent statistics from the
American Society for Aesthetic Plastic Surgery. ${ }^{29}$ However, individuals seeking treatment are not limited to this age range, with the treatment of expression wrinkles being a particularly popular procedure among Russian women in the 25 - to 35-year age group. ${ }^{28}$

In addition, there may be specific facial characteristics that Russians tend to prefer, such as arched eyebrows and an oval facial shape, that result in increased demand in Russia for particular aesthetic procedures.

The aim of this publication was to develop the first practical recommendations for the Russian population on the optimal dose of incobotulinumtoxinA and injection techniques for various treatment areas of the upper and lower face to achieve the expected aesthetic outcome. These recommendations are based on the findings of two multidisciplinary expert consensus meetings held to discuss the optimal dosage of incobotulinumtoxinA for the treatment of mimic wrinkles of the upper and lower face. At these meetings, the experts also discussed the practical implications of the recommendations for daily clinical practice and dose adjustments related to sex and age, as well as techniques to minimize adverse events.

\section{Consensus group and methodology}

The expert consensus meetings were held on November 17, 2013, and on March 11, 2014, and were comprised of experienced practitioners in the fields of dermatology and/or plastic surgery. Individuals were selected to be part of the panel based on a literature search, their practice and familiarity with the use of incobotulinumtoxinA, and their international expertise. On average, consensus group members had used BoNT/A in aesthetics for 15 years.

Before reaching consensus on the use of incobotulinumtoxinA in facial aesthetics, the expert group reviewed and analyzed the existing literature and previous consensus recommendations (eg, two global consensuses, German guidelines and a French consensus $)^{16,22-25,30,31}$ and discussed the extensive practical experience among the panel in the use of incobotulinumtoxinA in aesthetics. A list of relevant literature for the experts to review was compiled through searching PubMed (National Center for Biotechnology Information, Bethesda, MD, USA). Searches were based around the following search string: ([IncobotulinumtoxinA OR Xeomin] AND aesthetics) NOT blepharospasm NOT pain NOT cervical dystonia NOT sialorrhea NOT dentistry NOT headache NOT bladder NOT stroke NOT hyperhidrosis NOT toe NOT palsy NOT spasticity NOT spasmodic.

After expert discussions on the available data, open voting took place on a number of potential recommendations. 
The recommendations presented in these guidelines reflect a high level of agreement ( $>90 \%$ ) among all expert panel members.

\section{Overview}

The four BoNT/A preparations available in Russia may differ not only in terms of formulation but also in terms of their relative efficacy and tolerability profiles..$^{13-15,30,32}$ It is important to understand the similarities and differences between available BoNT/A products, as this enables clinicians to make informed decisions about their most appropriate applications in clinical practice.

It is important to note that these guidelines are only based on the use of incobotulinumtoxinA for facial aesthetics. However, based on their clinical experience, the consensus group agreed that onabotulinumtoxin A and incobotulinumtoxinA could be used at a 1:1 dose ratio, as suggested previously. ${ }^{25,30,31}$ Considering the dosing for glabellar frown lines, a ratio of 2.5:1 for abobotulinumtoxinA and incobotulinumtoxinA was considered appropriate and in agreement with other consensus recommendations. ${ }^{25,30,31}$ Head-to-head comparisons of incobotulinumtoxinA and onabotulinumtoxinA have reported the products to have equivalent efficacy when used at the same dose for the treatment of periocular rhytides and masseteric hypertrophy, ${ }^{33}$ for the treatment of focal hyperhidrosis,${ }^{34}$ and for the treatment of glabellar frown lines at respective concentrations of $30 \mathrm{U}$ and $20 \mathrm{U},{ }^{35}$ at a $3: 1$ respective dose ratio, ${ }^{8}$ and at respective concentrations of $20 \mathrm{U}$ and $30 \mathrm{U}^{36}$

\section{Clinical characteristics of BoNT/A products}

All experts agreed that, with correct dosing and conversion ratios, clinically, there are no differences in the efficacy and duration of treatment effect between these four BoNT/As.

When considering immunogenicity, experts also agreed that clinical insensitivity (reduced or lack of clinical effect) to BoNT/A and secondary treatment failure can be caused by the formation of neutralizing antibodies. Thus, as foreign proteins may play an important role in immunogenicity, the complexing protein-free formulation of incobotulinumtoxinA was viewed as a clinical advantage by the experts.

\section{Consensus guidelines by indication/treatment areas}

The following consensus recommendations are provided for two major facial zones, according to application in the daily aesthetics practice: the upper face and the lower face.

\section{Upper face}

Table 1 summarizes the recommended total treatment dose for each of the indications discussed.

\section{Glabellar lines/glabellar frown lines}

BoNT/A preparations are often used to lessen the action of the procerus and corrugator muscles in the face. This procedure reduces the appearance of vertical and horizontal hyperkinetic lines in the glabellar region, which, if exaggerated, are known to give the false impression of negative emotions. ${ }^{37}$

It is important to examine fully the involvement of the muscles at rest and contraction. It is not always necessary to inject the procerus muscle; in fact, it should be injected only if horizontal lines appear in the glabellar region on contraction. The consensus group agreed on an optimal starting dose of $20 \mathrm{U}$, to be adjusted to the individual. Typically, five to six injection points (Figure 1A) are used if the procerus is to be injected, with the dose distributed equally between the injection sites. The experts recommend deep intramuscular injections into the procerus, with one to two injection points in the myogaster at the intersection of the lines from the medial tip of the brow to the inner corner of the eye. If the corrugator muscle is to be injected, the experts recommend two injection points on each side: the first at the point of maximum muscular contraction, deep in the head of the corrugator, and the second more lateral and superficial. For both the procerus and corrugator muscle injections, the needle should be inserted perpendicular to the surface.

Lid and/or brow ptosis are possible adverse events associated with this treatment. To minimize the risk of such events, injections into the tail of the corrugator muscles or at the subdermal insertion points should be kept superficial.

\section{Periorbital lines/crow's feet/lateral canthal lines}

Crow's feet, which are characterized by fine wrinkles at the corners of the eyes, are often identified as one of the first visible signs of aging on the face. These lines can occur as early as the late $20 \mathrm{~s}$, and even earlier in individuals who

Table I Summary of the consensus panel's recommendations on the optimal total treatment doses of incobotulinumtoxinA within each upper facial indication

\begin{tabular}{ll}
\hline Indication & $\begin{array}{l}\text { Injection dose, units of } \\
\text { incobotulinumtoxinA }\end{array}$ \\
\hline Glabella & 20 \\
Crow's feet & 12 (per eye area) \\
Forehead lines & $10-20$ \\
Bunny lines & $2-4$ (per side of face) \\
\hline
\end{tabular}




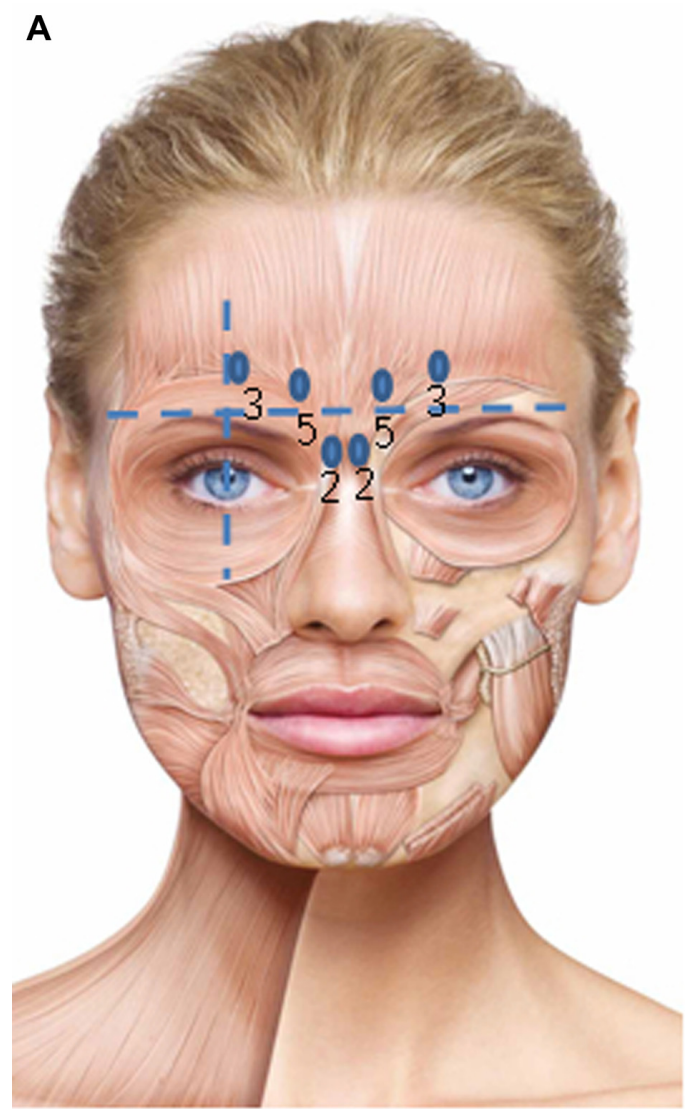

C

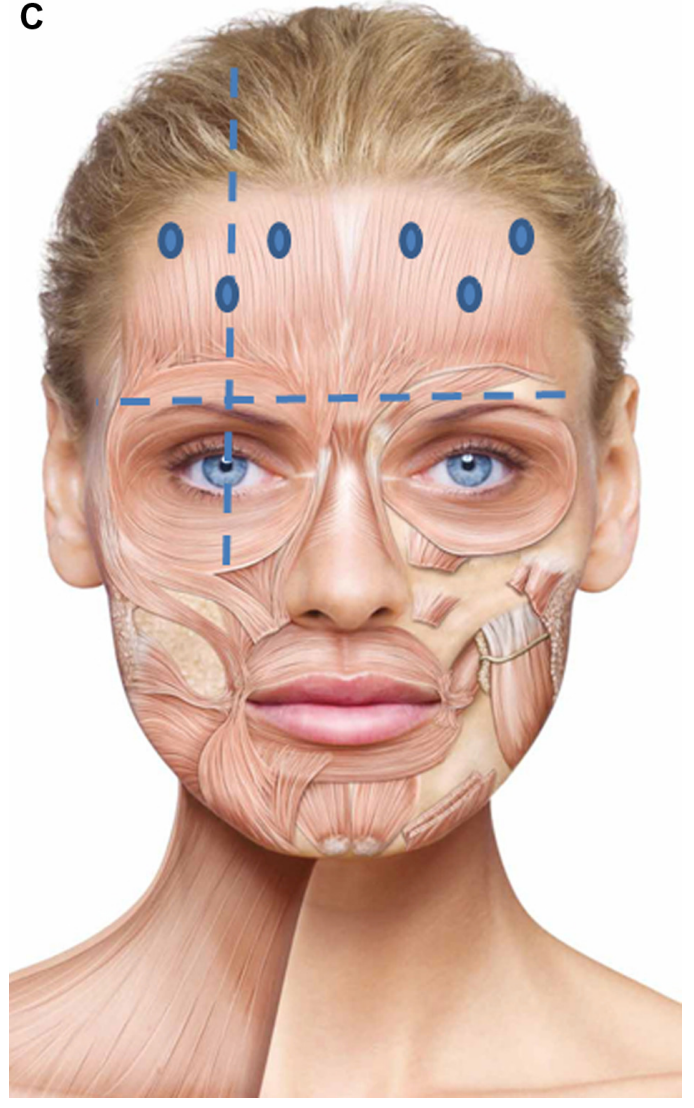

B
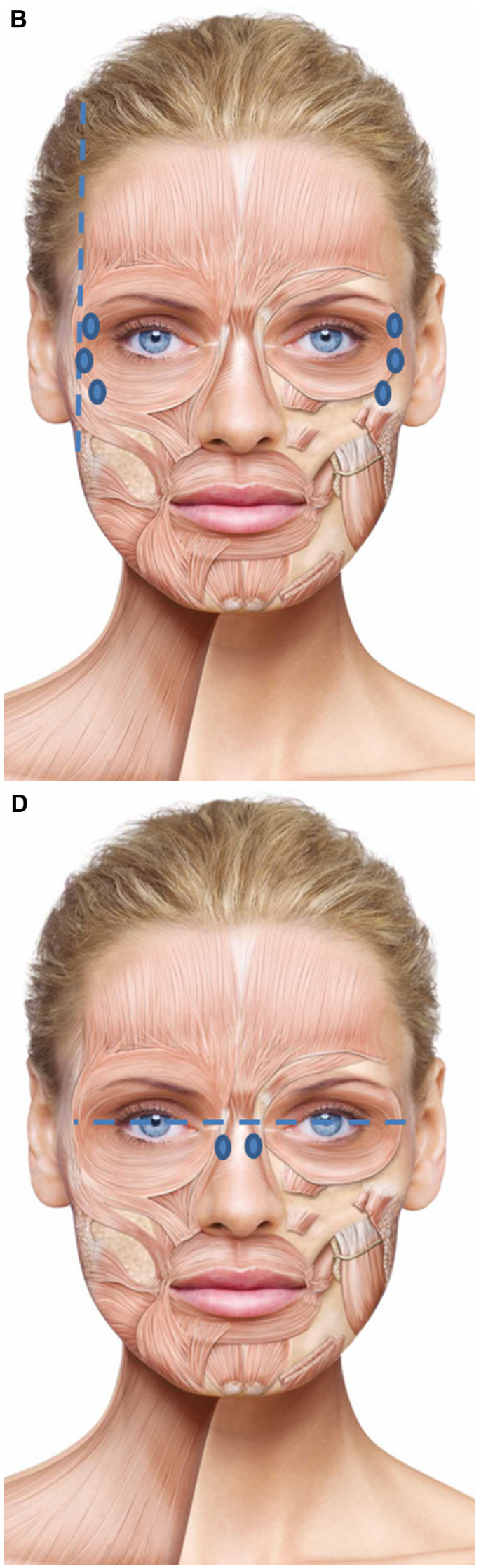

Figure I Injection sites to treat each upper facial indication, as recommended by the expert panel.

Notes: Recommended injection sites for $(\mathbf{A})$ glabellar lines, a total dose of $20 \mathrm{U}$ is recommended, and divided between 6 injection sites, with the numbers 2 , 3, and 5 indicating the dose in $U$ per site; (B) periorbital lines/crow's feet; (C) forehead wrinkles; (D) bunny lines. Copyright 2015 @ Merz Pharmaceuticals. Reproduced with permission from Merz Pharmaceuticals GmbH. 
frequently squint. ${ }^{38}$ Crow's feet develop as a result of the action of the orbital portion of the orbicularis oculi muscles and are accentuated by contraction of the zygomaticus and zygomatic head of the quadratus labii superioris muscle, which elevates the upper cheek. ${ }^{38}$ Crow's feet are most pronounced when using the muscles around the eyes; BoNT/A preparations can help relax these muscles, and therefore reduce their appearance.

It is important to conduct a thorough clinical examination of the crow's feet at rest and at maximum contraction, and to assess the involvement of the different muscles so that dose and injection site can be adjusted accordingly. The experts agreed on a standard total treatment dose of $12 \mathrm{U}$ per side, split between three to four injection sites (see Figure 1B). The injection should be superficial and at a position $1 \mathrm{~cm}$ from the lateral orbital edge, to the lateral portion of the orbicularis oculi muscle, and the needle should be directed away from the orbit. A deeper injection should be used for hyperkinetic muscle phenotypes.

\section{Forehead wrinkles}

Horizontal lines on the forehead, created by the action of the frontalis muscle, deepen during the fourth decade of life, ${ }^{38}$ and application of BoNT/A to the frontalis can reduce the appearance of these wrinkles.

Treatment of this muscle, which is the only brow elevator, is becoming more sophisticated, and optimal results can be achieved by retaining partial muscle activity to allow some facial expression. ${ }^{31}$ The consensus group recommends a total treatment dose of 10-20 U incobotulinumtoxinA split across four to eight injection sites (2-4 U per point). The injections should be delivered intramuscularly at the sites shown in Figure 1C. Injections should be at least $1.5-2 \mathrm{~cm}$ above the eyebrow line and at least $2-2.5 \mathrm{~cm}$ above the orbit edge in a staggered, V-shaped, or linear arrangement.

\section{Bunny lines}

Preparations of BoNT/A can be used to reduce the contraction of the transverse portion of the nasalis; overcontraction of this area is known to result in bunny lines. ${ }^{39}$ In some countries, bunny lines are not considered to be negative features or signs of aging, and as a consequence, they are not frequently treated. Although this treatment is not commonly performed in Russia, the consensus group agreed on two injection sites (Figure 1D) in the nasalis and a total treatment dose of 2-4 U incobotulinumtoxinA for each side of the face. Superficial intramuscular injections should be administered at the border of the dorsum and wing of the nose at the point of maximum muscular contraction.

\section{Lower face}

Table 2 summarizes the recommended total treatment dose for each of the indications discussed.

\section{Perioral wrinkles}

Traditionally, the aged perioral region has been rejuvenated by surgery, chemical peels, and laser resurfacing. BoNT/A offers a less invasive, nonsurgical option for those who wish to reduce the signs of perioral wrinkles. BoNT/A preparations achieve this by inhibiting contraction of some of the key muscles responsible for perioral rhytides. $^{40}$

Hyperactivity of the orbicularis oris muscle is partly responsible for generating the fine wrinkles that radiate out from the lips. Because it is a circular muscle with fibers above and below the mouth, it is usually advisable to treat both the upper and lower portions to maintain balance, and injections should be kept symmetrical and superficial. ${ }^{31}$ For treatment of the upper lip, the experts recommend a total treatment dose of 4-6 U for the whole area. This should be split among four injection sites (1-1.5 U per point; Figure 2A). Injections should be positioned on the vermillion border of the upper lip at least $1 \mathrm{~cm}$ from the mouth corner, avoiding the philtrum column area. The needle should be injected parallel to the skin surface.

\section{Depressor anguli oris}

The action of the depressor anguli oris (DAO), which originates at the oral commissure and extends obliquely to join fibers of the platysma, ${ }^{41}$ leads to vertical marionette lines that project downward from the corners of the mouth. ${ }^{42}$

Injection of the DAO is an important component of rebalancing the lower third of the face. An optimal total treatment dose of $6 \mathrm{U}$ (range, 3-8 U) was recommended, divided between two injection sites, one per side. Superficial intramuscular injections are recommended in the lower third of the DAO, with the needle directed laterally. As shown in Figure 2B, the injection points are located in the

Table 2 Summary of the consensus panel's recommendations on the optimal total treatment doses of incobotulinumtoxinA within each lower facial indication

\begin{tabular}{ll}
\hline Indication & $\begin{array}{l}\text { Injection dose, units of } \\
\text { incobotulinumtoxinA }\end{array}$ \\
\hline Perioral wrinkles (upper lip) & $4-6$ \\
Depressor anguli oris & 6 \\
Mentalis & 6 \\
Masseter & 50 \\
Nefertiti lift & 20 (per half of the face) \\
Platysmal bands & $50-60$ \\
\hline
\end{tabular}


A
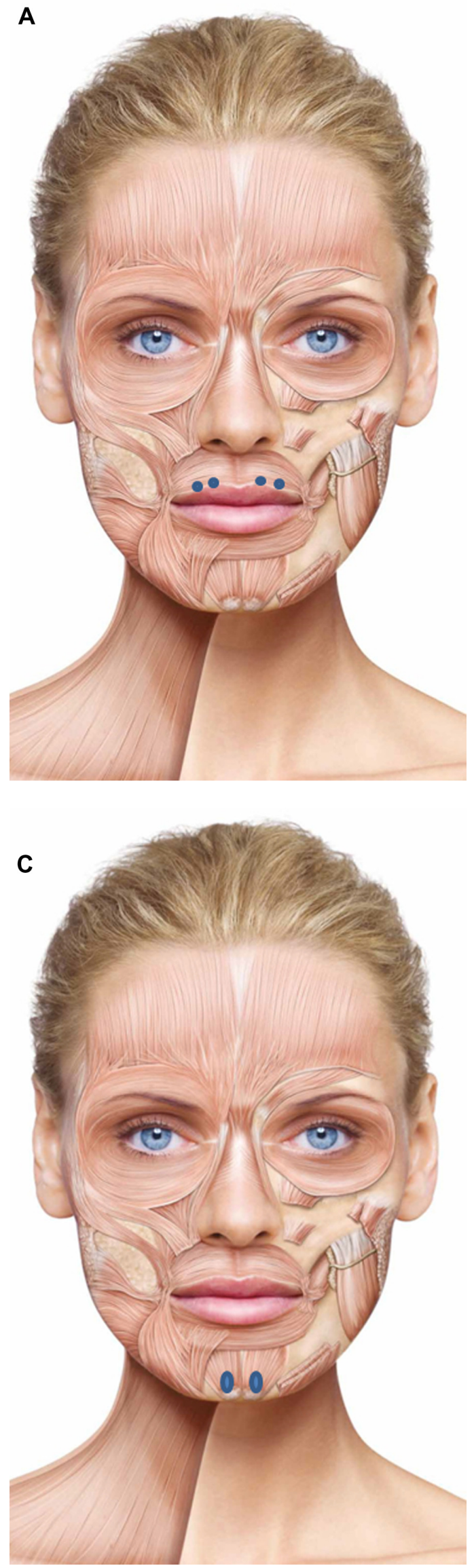

B

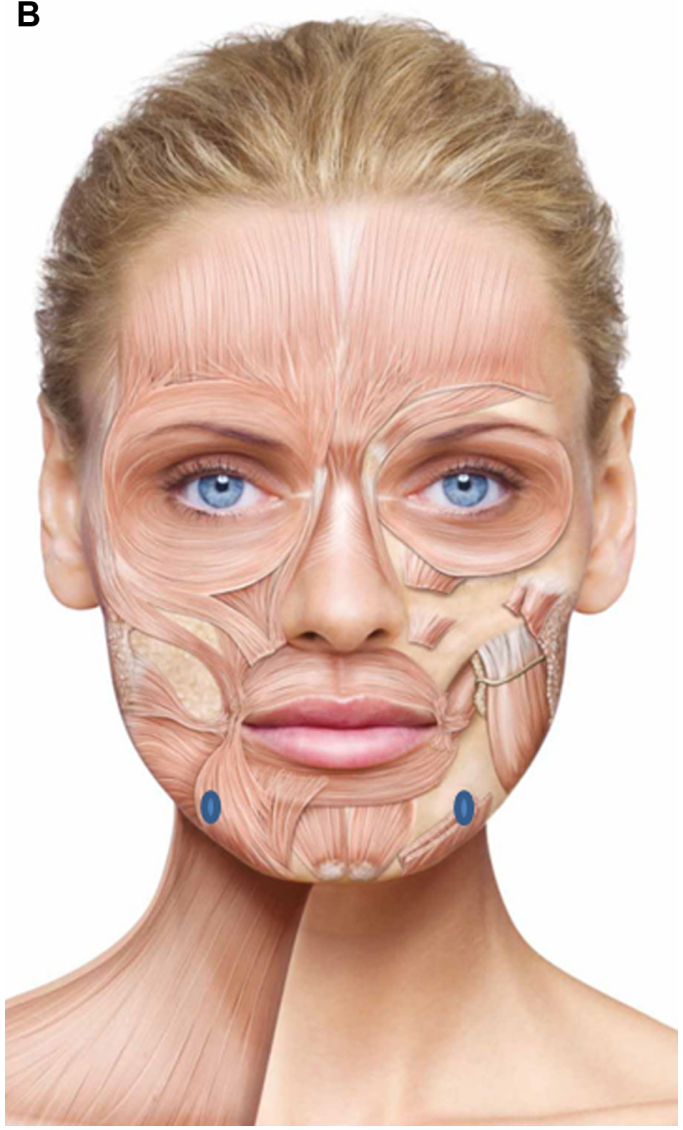

D

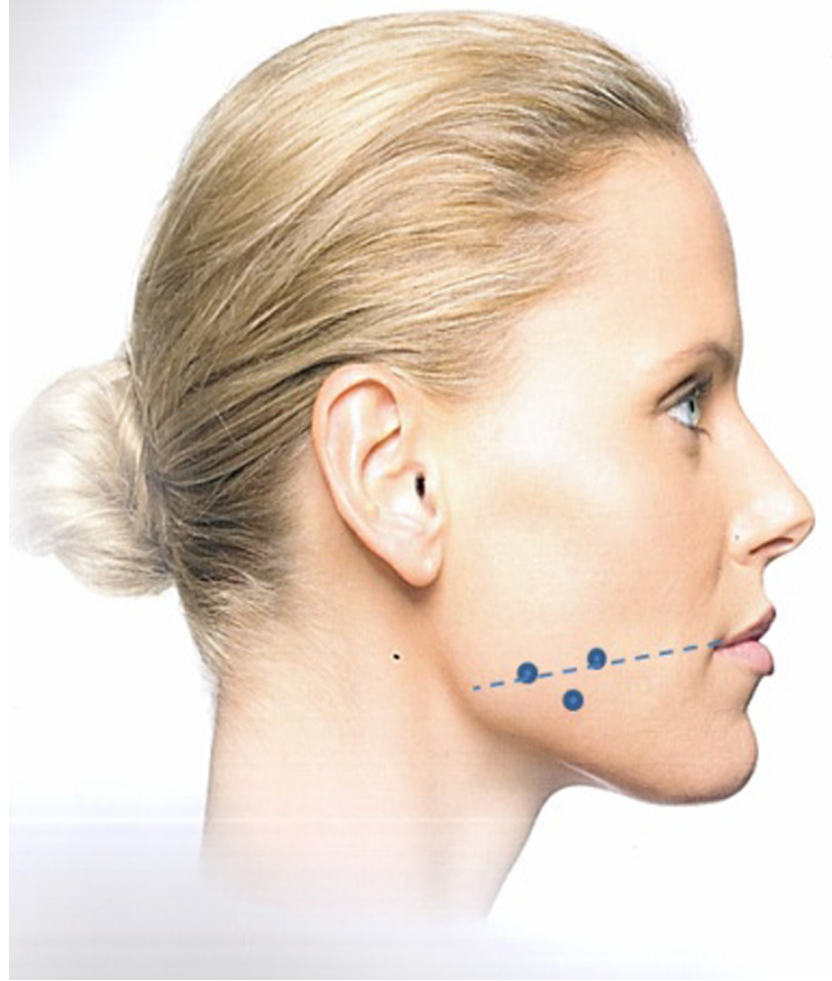

Figure 2 (Continued) 

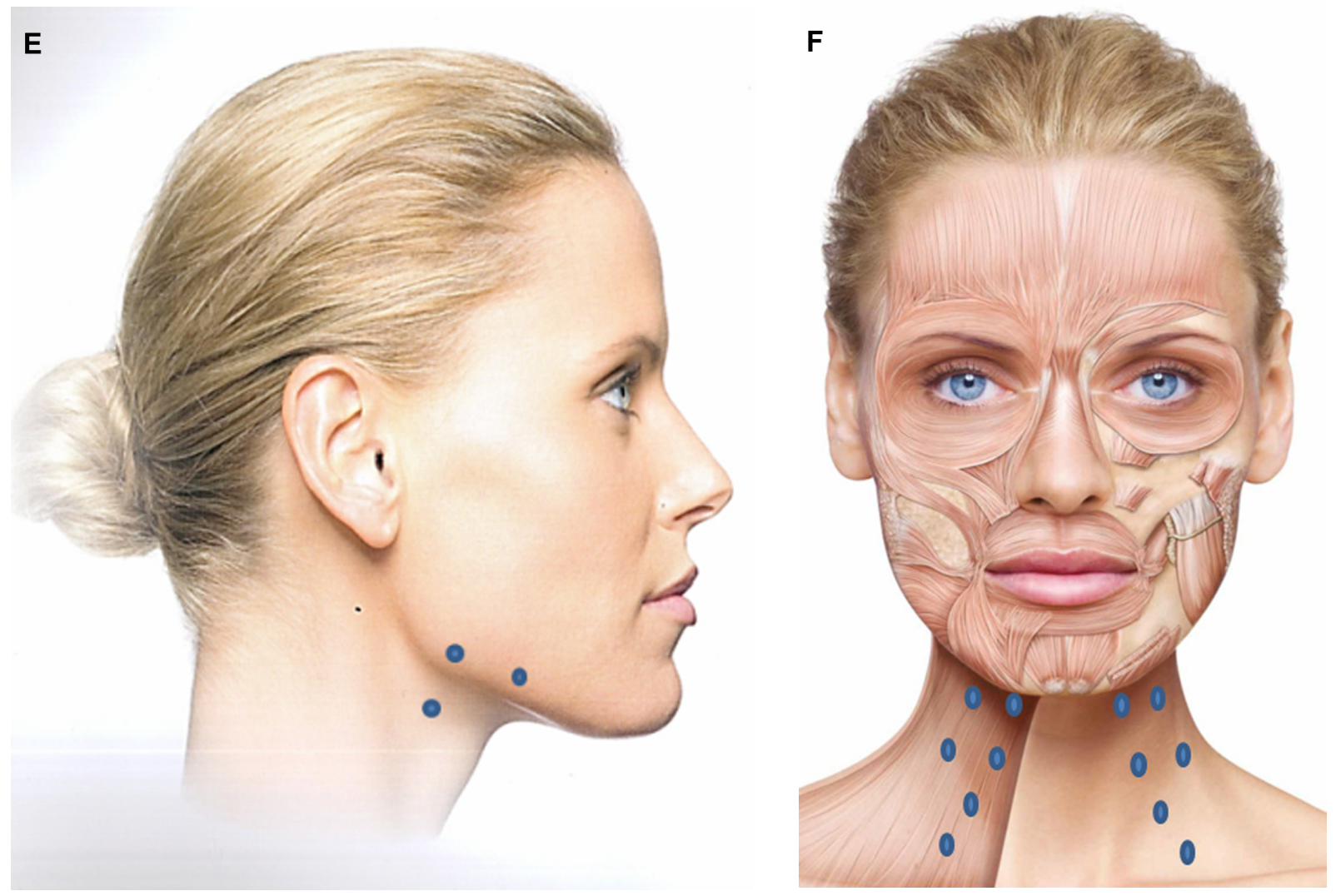

Figure 2 Injection sites to treat each lower facial indication, as recommended by the expert panel.

Notes: Recommended injection sites for (A) perioral wrinkles; (B) depressor anguli oris; (C) mentalis; (D) masseters; (E) Nefertiti lift; (F) platysmal bands. Copyright 2015 (C) Merz Pharmaceuticals. Reproduced with permission from Merz Pharmaceuticals GmbH.

projection of the DAO, $1 \mathrm{~cm}$ lateral and $1.5 \mathrm{~cm}$ below the oral commissure.

\section{Mentalis}

Cosmetic BoNT/As have been shown to be effective in the treatment of moderate rhytides of the mentalis for individuals who exhibit significant, dynamic chin wrinkles. ${ }^{43}$ Contraction of the mentalis raises the chin and can cause a deep crease between the lower lip and the prominence of the mandible. In addition, with loss of collagen and fat in the chin that occurs with aging, the chin can also appear dimpled.

The consensus group agreed on an optimal total treatment dose of $6 \mathrm{U}$ incobotulinumtoxinA (range, 2-8 U), divided equally between two injection sites, one per side. Deep intramuscular injections are recommended at two symmetrical points located $1 \mathrm{~cm}$ above the jawline, close to the chin midline (Figure 2C). The experts recommend that the needle be held at a perpendicular angle, with one-third of the needle inserted into the mentalis.

\section{Masseters}

Large masseter muscles can give an overly square shape to the face, and BoNT/A can be used to contour this area. ${ }^{44}$
BoNT/A treatment allows the masseter muscles to relax and become smaller over time, providing a more attractive shape to the lower face. ${ }^{4}$

A careful clinical examination should be carried out to ensure that a square jaw contour is a consequence of masseter muscle hyperactivity, rather than a nonmuscular cause, such as a bony prominence, which cannot be treated with BoNT/A. The consensus group agreed on a total treatment dose of $50 \mathrm{U}$, split across two to three injection sites per side, with a recommended dose of 8-10 U per injection site. Deep intramuscular injections are recommended at the sites shown in Figure 2D. The injection sites are evenly distributed across the area of greatest masseter contraction; the site is located on the line connecting the mouth corner and the mandibular angle at $1-1.5 \mathrm{~cm}$ from the mandibular angle. The second point is located on the same line outward from the medial masseter margin. A minimum of the first third of the needle should be inserted at an angle perpendicular to the skin surface.

\section{Nefertiti lift}

The Nefertiti lift employs BoNT/A to redefine the jawline. This procedure aims to counteract the effects caused by a 
combination of loss of skin elasticity resulting from aging and gravity. ${ }^{45}$

During examination, the individual is requested to grimace, thus inducing contraction of the platysma. If this action results in the disappearance of the mandibular contour, then the patient is deemed to be a suitable candidate for treatment. ${ }^{45}$ An optimal total treatment dose of $20 \mathrm{U}$ incobotulinumtoxinA was agreed for each half of the face. In total, two to three injection sites per half of the face are recommended, with a maximum dose of 6-10 U per point. Superficial intramuscular injections should be used at the sites on the jawline presented in Figure 2E. The first site is $0.5-1 \mathrm{~cm}$ lateral from the mandibular ligament projection, and the second is $2 \mathrm{~cm}$ further and lateral from the first site, with a third additional site positioned to the upper edge of the lateral platysmal band to be used if the platysmal bands are hypertonic.

\section{Platysmal bands}

Banding of the platysmal muscle is a consequence of chronic muscular contraction and skin laxity in the neck resulting from aging. Historically, surgery has been the only option for patients who want to improve the appearance of platysmal banding. However, BoNT/A preparations have shown efficacy for the treatment of this muscle. ${ }^{46-48}$

Patient selection is key to successful treatment, as only those who have retained sufficient skin elasticity without too much submental fat will benefit; these patients tend to be younger. ${ }^{31}$ The recommended total treatment dose is $50 \mathrm{U}$ incobotulinumtoxinA, but this depends on how many bands there are to treat. The initial recommended dose for treatment of pronounced bands is $15-20 \mathrm{U}$ per band, or 10 $\mathrm{U}$ per band for mild cases. In total, 12 injection sites are recommended, with a maximum dose of 2-5 $\mathrm{U}$ per point. Injections should be superficial, with the needle inserted directly into the platysmal bands at the sites shown in Figure 2F. Briefly, four injections are recommended in the medial bands, with the needle directed outward. A further two injection sites on each side are on lateral bands, with the needle directed inward. The sites are located $2 \mathrm{~cm}$ apart, and the needle should be directed parallel to the skin surface.

Although this is the first Russian consensus on incobotulinumtoxinA optimal dose recommendation in aesthetics, it is important to note that these doses are in line with existing recommendations and guidelines, as well as international clinical practice.

\section{Considerations to maximize patient satisfaction}

Further to agreeing on the optimal recommended treatment doses, the consensus panel discussed situations in which the optimal effect might not be achieved.

The panel agreed that repeated administration of BoNT/A within short time periods (typically more frequently than every 2-3 months) may cause BoNT/A immunogenicity and reduce the treatment effect.

An important consideration in the administration of BoNT/A is muscle activity. The treatment effect, and consequentially patient satisfaction, is increased when the dose is adjusted according to the type of muscle activity. For instance, when treating the glabellar, men tend to have a higher muscle mass, and therefore may require higher doses than women. Similarly, younger individuals with lower muscle mass may require lower doses. The experts' recommended standard dose should be used for the kinetic muscle type. For the hyperkinetic muscle types typically displayed in most men, the experts recommend a dose increase of 1.5 times or more. Combined treatment with fillers is recommended for hypertonic muscle types. The experts agreed that older patients do not require a reduced dose of BoNT/A, feeling it is more prudent to assess type of muscle activity, rather than patient age.

On the basis of the experts' clinical experience, it was agreed that patients should be advised to expect a shorter treatment duration in the lower face than the upper face.

Lastly, when switching the BoNT/A product, the dose selection depends on the type of muscle activity of the patient, and the recommended doses for each toxin should be used.

\section{Safety: adverse events}

In general, BoNT/As such as incobotulinumtoxinA have good safety profiles. ${ }^{1,2}$ The most common adverse events tend to be pain at the injection site, swelling, and headache, but these are generally mild and transient ${ }^{49}$ and simple steps can be taken to minimize their occurrence. Regularly changing needles, using small-gauge needles, and good technique can minimize pain, and some patients may find ice or a topical anesthetic beneficial. Application of ice can also help to minimize bruising, and over-the-counter medicines can be used to treat headache.

The most reliable way to avoid complications is to ensure a clear understanding of facial anatomy and the three-dimensional changes that occur with aging. The lower face, for example, has many integrated muscles involved in essential activities such as eating, and extra care should be 
taken when executing injection strategies in these areas to avoid complications.

\section{Summary and conclusion}

BoNT/A is a very popular, nonsurgical tool available to aesthetic clinicians and can be an effective treatment to satisfy the goals of individuals seeking cosmetic enhancement. After a review of the clinical data and sharing of expertise, the consensus group agreed that incobotulinumtoxinA was an effective treatment for a range of wrinkles of the upper and lower face. The recommendations given here are the first practical guidelines of optimal starting doses, specifically for clinicians using incobotulinumtoxinA to achieve the expected and optimal aesthetics outcome.

\section{Acknowledgments}

The expert meetings were funded by Merz Pharmaceuticals $\mathrm{GmbH}$. Editorial support for manuscript development was provided by SCI Scientific Communications \& Information, Oxford, UK, and funded by Merz Pharmaceuticals GmbH.

\section{Disclosure}

Yana Yutskovskaya is a consultant for, and serves on advisory boards for Merz Aesthetics; and reports no other conflicts of interest in this work. Elena Gubanova is a scientific advisory board member for Ipsen, an international trainer for Restylane $^{\circledR}$ (Q-MED), and is a consultant for Merz Russia. The other authors report no conflicts of interest in this work.

\section{References}

1. Carruthers A, Carruthers J, Coleman WP III, et al. Multicenter, randomized, phase III study of a single dose of incobotulinumtoxinA, free from complexing proteins, in the treatment of glabellar frown lines. Dermatol Surg. 2013;39(4):551-558.

2. Hanke CW, Narins RS, Brandt F, et al. A randomized, placebo-controlled, double-blind phase III trial investigating the efficacy and safety of incobotulinumtoxinA in the treatment of glabellar frown lines using a stringent composite endpoint. Dermatol Surg. 2013;39(6):891-899.

3. Imhof M, Kühne U.A Phase III study of incobotulinumtoxinA in the treatment of glabellar frown lines. J Clin Aesthet Dermatol. 2011;4(10):28-34.

4. Lee JH, Park JH, Lee SK, et al. Efficacy and safety of incobotulinum toxin A in periocular rhytides and masseteric hypertrophy: side-byside comparison with onabotulinum toxin A. J Dermatolog Treat. 2014;25(4):326-330.

5. Oliveira de Morais O, Matos Reis-Filho E, Vilela Pereira L, Martins Gomes C, Alves G. Comparison of four botulinum neurotoxin type A preparations in the treatment of hyperdynamic forehead lines in men: a pilot study. J Drugs Dermatol. 2012;11(2):216-219.

6. Prager W, Bee EK, Havermann I, Zschocke I. Onset, longevity, and patient satisfaction with incobotulinumtoxinA for the treatment of glabellar frown lines: a single-arm, prospective clinical study. Clin Interv Aging. 2013;8:449-456.

7. Prager W, Wissmüller E, Kollhorst B, Williams S, Zschocke I. Comparison of two botulinum toxin type A preparations for treating crow's feet: a split-face, double-blind, proof-of-concept study. Dermatol Surg. 2010;36(Suppl 4):2155-2160.
8. Sattler G, Callander MJ, Grablowitz D, et al. Noninferiority of incobotulinumtoxinA, free from complexing proteins, compared with another botulinum toxin type $\mathrm{A}$ in the treatment of glabellar frown lines. Dermatol Surg. 2010;36(Suppl 4):2146-2154.

9. Carruthers JA, Lowe NJ, Menter MA, et al; BOTOX Glabellar Lines I Study Group. A multicenter, double-blind, randomized, placebo-controlled study of the efficacy and safety of botulinum toxin type A in the treatment of glabellar lines. J Am Acad Dermatol. 2002;46(6): 840-849.

10. Carruthers JD, Lowe NJ, Menter MA, Gibson J, Eadie N; Botox Glabellar Lines II Study Group. Double-blind, placebo-controlled study of the safety and efficacy of botulinum toxin type A for patients with glabellar lines. Plast Reconstr Surg. 2003;112(4):1089-1098.

11. Lowe NJ, Ascher B, Heckmann M, Kumar C, Fraczek S, Eadie N; Botox Facial Aesthetics Study Team. Double-blind, randomized, placebocontrolled, dose-response study of the safety and efficacy of botulinum toxin type A in subjects with crow's feet. Dermatol Surg. 2005;31(3):257-262.

12. Ascher B, Rzany BJ, Grover R. Efficacy and safety of botulinum toxin type A in the treatment of lateral crow's feet: double-blind, placebo-controlled, dose-ranging study. Dermatol Surg. 2009;35(10): 1478-1486.

13. Bocouture ${ }^{\circledR}$. Summary of Product Characteristics. Merz Pharmaceuticals GmbH, Germany; 2012.

14. Lantox Botulinum Toxin Type A [Homepage on the Internet]. Lantox, Медицина и косметология [Lantox, Health and Beauty]. Available from: http://www.lantox.ru. Accessed January 8, 2014. Russian.

15. Wenzel R, Jones D, Borrego JA. Comparing two botulinum toxin type A formulations using manufacturers' product summaries. J Clin Pharm Ther. 2007;32(4):387-402.

16. Carruthers A, Kane MA, Flynn TC, et al. The convergence of medicine and neurotoxins: a focus on botulinum toxin type A and its application in aesthetic medicine - a global, evidence-based botulinum toxin consensus education initiative: part I: botulinum toxin in clinical and cosmetic practice. Dermatol Surg. 2013;39(3 Pt 2):493-509.

17. First National Esthetic Portal. Botulinum toxin in Russia - Review. Available from: http://www.1nep.ru/en/articles/177070/. Accessed March 10, 2015.

18. Frevert J. Xeomin: an innovative new botulinum toxin type A. Eur $J$ Neurol. 2009;16(Suppl 2):11-13.

19. Lee JC, Yokota K, Arimitsu H, et al. Production of anti-neurotoxin antibody is enhanced by two subcomponents, HA1 and HA3b, of Clostridium botulinum type B $16 \mathrm{~S}$ toxin-haemagglutinin. Microbiology. 2005;151(Pt 11):3739-3747.

20. Solov'ev MM, Trezubov VN, Kudriavtseva TD, Protasevich AI, Raad Z, Shul'kina NM. Ekspertnaia ésteticheskaia otsenka litsa [The expert esthetic evaluation of the face]. Stomatologiia (Mosk). 1994;73(3): 42-46. Russian.

21. Carruthers J, Fagien S, Matarasso SL; Botox Consensus Group. Consensus recommendations on the use of botulinum toxin type a in facial aesthetics. Plast Reconstr Surg. 2004;114(Suppl 6):1S-22S.

22. Raspaldo H, Baspeyras M, Bellity P, et al; Consensus Group. Upper- and mid-face anti-aging treatment and prevention using onabotulinumtoxin $\mathrm{A}$ : the 2010 multidisciplinary French consensus - part 1. J Cosmet Dermatol. 2011;10(1):36-50.

23. Raspaldo H, Niforos FR, Gassia V, et al; Consensus Group. Lower-face and neck antiaging treatment and prevention using onabotulinumtoxin $\mathrm{A}$ the 2010 multidisciplinary French consensus - part 2. J Cosmet Dermatol. 2011;10(2):131-149.

24. Poulain B, Trevidic P, Clave M, et al. Clinical equivalence of conventional onabotulinumtoxinA $(900 \mathrm{KDa})$ and incobotulinumtoxin $\mathrm{A}$ (neurotoxin free from complexing proteins - 150 KDa): $2012 \mathrm{mul}-$ tidisciplinary French consensus in aesthetics. J Drugs Dermatol. 2013;12(12):1434-1446.

25. Leitlinie der Deutschen Dermatologischen Gesellschaft. Ästhetische Botulinumtoxin-Therapie [Guideline of the German Society of Dermatology. Aesthetic Botulinum Toxin Therapy]. Imhof M, Podda M, Sommer B. AWMF online; 2012. Available from: http://www.awmf.org/ uploads/tx_szleitlinien/013-0771_S1_\%C3\%84sthetische_Botulinumtoxin_Therapie_2012-11.pdf. Accessed March 10, 2015. German. 
26. Mostovaia A. Ideals of physical beauty in the prose of Russian women writers in the Soviet and post-Soviet era. Transcultural Studies. 2006-2007;2-3:153-171.

27. Gil-Robles A. Report by Mr Alvaro Gil-Robles, Commissioner for human rights, on his visits to the Russian Federation. Council of Europe; 2005. Available from: https://wcd.coe.int/ViewDoc.jsp?id=846655. Accessed January 12, 2014.

28. Cosmetics in Russia. Russian market for Botox and other minimallyinvasive procedures grows $20 \%$ annually. Available from: https://cosmeticsrussia.livejournal.com/2578.html. Accessed January 12, 2014.

29. The American Society for Aesthetic Plastic Surgery. Statistics. Available from: http://www.surgery.org/media/statistics. Accessed February 10, 2014.

30. Carruthers J, Fournier N, Kerscher M, Ruiz-Avila J, Trindade deAlmeidaAR, Kaeuper G. The convergence of medicine and neurotoxins: a focus on botulinum toxin type $\mathrm{A}$ and its application in aesthetic medicine a global, evidence-based botulinum toxin consensus education initiative: part II: incorporating botulinum toxin into aesthetic clinical practice. Dermatol Surg. 2013;39(3 Pt 2):510-525.

31. Lorenc ZP, Kenkel JM, Fagien S, et al. Consensus panel's assessment and recommendations on the use of 3 botulinum toxin type A products in facial aesthetics. Aesthet Surg J. 2013;33(Suppl 1):35S-40S.

32. Prager W. Differential characteristics of incobotulinumtoxinA and its use in the management of glabellar frown lines. Clin Pharmacol. 2013;5: 39-52.

33. Lee JH, Park JH, Lee SK, et al. Efficacy and safety of incobotulinum toxin A in periocular rhytides and masseteric hypertrophy: side-byside comparison with onabotulinum toxin A. J Dermatolog Treat. 2014;25(4):326-330.

34. CampanatiA, Giuliodori K, Martina E, Giuliano A, Ganzetti G, Offidani A. Onabotulinumtoxin type A (Botox ${ }^{\mathbb{B}}$ ) versus incobotulinumtoxin type A $\left(\mathrm{Xeomin}^{\mathbb{B}}\right)$ in the treatment of focal idiopathic palmar hyperhidrosis: results of a comparative double-blind clinical trial. J Neural Transm. 2014;121(1):21-26.

35. Moers-Carpi M, Dirschka T, Feller-Heppt G, et al. A randomised, double-blind comparison of 20 units of onabotulinumtoxinA with 30 units of incobotulinumtoxinA for glabellar lines. J Cosmet Laser Ther. 2012;14(6):296-303.
36. Prager W, Rappl T. Phase IV study comparing incobotulinumtoxinA and onabotulinumtoxinA using a 1:1.5 dose-conversion ratio for the treatment of glabellar frown lines. J Cosmet Dermatol. 2012;11(4): 267-271.

37. Cox SE, Finn JC. Social implications of hyperdynamic facial lines and patient satisfaction outcomes. Int Ophthalmol Clin. 2005;45(3): 13-24.

38. Fedok FG. The aging face. Facial Plast Surg. 1996;12(2):107-115.

39. Shetty MK, IADVL Dermatosurgery Task Force. Guidelines on the use of botulinum toxin type A. Indian J Dermatol Venereol Leprol. 2008;74(Suppl):S13-S22.

40. Suryadevara AC. Update on perioral cosmetic enhancement. Curr Opin Otolaryngol Head Neck Surg. 2008;16(4):347-351.

41. Fagien S, Raspaldo H. Facial rejuvenation with botulinum neurotoxin: an anatomical and experiential perspective. J Cosmet Laser Ther. 2007;9(Suppl 1):23-31.

42. Carruthers JD, Glogau RG, Blitzer A; Facial Aesthetics Consensus Group Faculty. Advances in facial rejuvenation: botulinum toxin type a, hyaluronic acid dermal fillers, and combination therapies - consensus recommendations. Plast Reconstr Surg. 2008;121(5 Suppl):5S-30S.

43. Beer K, Yohn M, Closter J. A double-blinded, placebo-controlled study of Botox for the treatment of subjects with chin rhytids. J Drugs Dermatol. 2005;4(4):417-422.

44. Lowe NJ, Yamauchi P. Cosmetic uses of botulinum toxins for lower aspects of the face and neck. Clin Dermatol. 2004;22(1):18-22.

45. Levy PM. The 'Nefertiti lift': a new technique for specific re-contouring of the jawline. J Cosmet Laser Ther. 2007;9(4):249-252.

46. Gubanova EI, Panova OS, Sanchez EA, Rodina MY, Starovatova PA. Efficacy and safety of incobotulinumtoxinA for the treatment of platysmal bands of the aging neck: an open-label, prospective pilot study. J Drugs Dermatol. 2013;12(12):1461-1466.

47. Kane MA. Nonsurgical treatment of platysma bands with injection of botulinum toxin a revisited. Plast Reconstr Surg. 2003;112(Suppl 5): $125 \mathrm{~S}-126 \mathrm{~S}$.

48. Matarasso A, Matarasso SL, Brandt FS, Bellman B. Botulinum A exotoxin for the management of platysma bands. Plast Reconstr Surg. 2003;112(Suppl 5):127S-134S.

49. Hirsch R, Stier M. Complications and their management in cosmetic dermatology. Dermatol Clin. 2009;27(4):507-520, vii.
Clinical, Cosmetic and Investigational Dermatology

\section{Publish your work in this journal}

Clinical, Cosmetic and Investigational Dermatology is an international, peer-reviewed, open access, online journal that focuses on the latest clinical and experimental research in all aspects of skin disease and cosmetic interventions. All areas of dermatology will be covered; contributions will be welcomed from all clinicians and

\section{Dovepress}

basic science researchers globally. This journal is indexed on CAS The manuscript management system is completely online and includes a very quick and fair peer-review system, which is all easy to use. Visit http://www.dovepress.com/testimonials.php to read real quotes from published authors. 